\title{
A Saturated-unsaturated Coupling Model for Groundwater Flowing into Seepage Wells: A Modeling Study for Groundwater Development in River Basins
}

\author{
Xianmin Ke \\ Chang'an University \\ Wei Wang ( $\square$ wangweichd@chd.edu.cn ) \\ Chang'an University https://orcid.org/0000-0002-4371-5714 \\ Xiangdong Xu \\ Chang'an University \\ Jinlong Li \\ Chang'an University \\ Haiyang Hu \\ Wuhan city
}

\section{Research Article}

Keywords: Saturated-unsaturated coupling model, Groundwater, Unsaturated zone, Drawdown, Physical simulation test

Posted Date: May 28th, 2021

DOl: https://doi.org/10.21203/rs.3.rs-493994/v1

License: (c) (i) This work is licensed under a Creative Commons Attribution 4.0 International License.

Read Full License 
A saturated-unsaturated coupling model for groundwater flowing into seepage wells: a modeling study for groundwater development in river basins

Xianmin $\mathrm{Ke}^{\mathrm{a}, \mathrm{b}}$, Wei Wang ${ }^{\mathrm{a}, \mathrm{b}^{*}}$, Xiangdong Xua ${ }^{\mathrm{a}, \mathrm{b}}$, Jinlong $\mathrm{Li}^{\mathrm{a}, \mathrm{b}}$, Haiyang $\mathrm{Hu}^{\mathrm{c}}$

a. School of Water and Environment, Chang'an University, Xi'an, 710054, Shaanxi, P.R.China

b. Key Laboratory of Subsurface Hydrology and Ecological Effect in Arid Region of the Ministry of Education, Chang'an University, Xi'an, 710054, Shaanxi, P.R.China

c. Wuhan Surveying-Geotechnical Research Institute Co., Ltd. of MCC

*Corresponding author: wangweichd@chd.edu.cn

\begin{abstract}
:
As a major and popular groundwater extraction structure, seepage wells are often used to transfer river water into aquifers for harvesting water resources. It can help ameliorate the imbalance between supply and demand, especially in areas of water shortage. Large drawdowns due to pumping may cause the river to disconnect from the groundwater and to form an unsaturated zone, which seriously affects the efficiency of seepage wells. However, most of the current models of extraction structures of non-tube wells only account for saturated flow and do not consider unsaturated conditions. To address this limitation, a saturated-unsaturated coupling model has been developed using the exchange flow rate between the well pipe and the aquifer as the coupling point. Moreover, the model was evaluated with physical simulation test data. The statistical results indicated that the model can estimate the drawdown and pumping rate well with root-mean-square deviations (RMSD) of $0.0114 \mathrm{~m}$ and $0.0079 \mathrm{~L} / \mathrm{s}$, respectively, for a river with strong leakage capacity, and $0.0129 \mathrm{~m}$ and $0.0099 \mathrm{~L} / \mathrm{s}$, respectively, for a river with weak leakage capacity. The critical drawdown, where the river disconnects from the aquifer, as well as variations of the unsaturated zone, is also discussed. The present study provides important information for the design of seepage wells with reasonable drawdown while being able to predict the potential water yield, and at the same time help protect the groundwater environment.
\end{abstract}




\section{Keywords:}

Saturated-unsaturated coupling model, Groundwater, Unsaturated zone, Drawdown, Physical simulation test

\section{Introduction}

Groundwater is one of the most important available water resources (Qiao et al., 2020; Wang et al., 2020) and is often harvested from aquifers in river basins where a huge population often resides (Li and Qian, 2013; Li et al., 2014). However, some river basins cannot supply a large quantity of water by using traditional wells because of low-yield capacity or thin aquifers. Studies have shown that seepage wells constructed near rivers can effectively solve this problem (Fu, 2012; Wang, 2013). Seepage wells are complex groundwater collecting structures, consisting of a shaft, galleries, chambers, and radiate pipes (Wang and Zhang, 2008), which can purify the river and drive river waters into aquifers via the sandy layer. Compared with a traditional well, seepage wells and other similar water extraction structures have many advantages, such as high production, low consumption, convenient management, and relatively low cost of water supply. Therefore, it is widely used as a means to increase water resources (Ameli and Craig, 2018; Maroney and Rehmann, 2017; Wu et al., 2019). Often, drawdown of the well is increased in the effort to obtain large water yields. However, it may lead to a disconnection between the groundwater aquifer and an associated river, thereby forming an unsaturated zone (Brunner et al., 2011; Cognac and Ronayne, 2020; Glennon, 2007; Sun, 2017; Wang et al., 2009; Xie et al., 2015). In this way, the water yield would not increase significantly, but the water extraction efficiency would decrease when the unsaturated zone appears (Chang et al., 2019 ).

Previous studies mainly focused on the problem of water intake from non-tube wells under saturated flow conditions. For these studies, models have been developed based on various assumptions. For example, non-pipe well water intake structures were characterized as an equal-flow or equal-head boundary to calculate the water yield (Hantush, 1961; Park and Zhan, 2003; Zhan et al., 2001). However, Chen et al. (2003) noted that the head in the well was not equally distributed due to head loss and established a coupled seepage-pipe flow model based 
on the equivalent hydraulic conductivity. The coupled seepage-pipe flow model considered the head loss and has since been widely applied (Lee et al., 2010; Sun, 2015; Zhang et al., 2008). Wang and Zhang (2008) established a calculation model of seepage wells based on the theory of equivalent hydraulic conductivity and a coupled seepage-pipe flow model. However, this model can only calculate a single seepage well due to the need for fine subdivisions. Therefore, Wang et al. (2013) improved the model by generalizing seepage wells as a series of nodes and pipes, which made the calculation of multiple seepage wells working simultaneously possible and reflected the coexistence of multiple flow regimes scientifically. Unfortunately, this improved model cannot correctly simulate how the infiltrated recharge from the river becomes a leaching recharge when the unsaturated zone occurs.

Studies about water intake in non-tube wells under unsaturated flow conditions are scarce. The few studies of unsaturated seepage of groundwater have provided an important guide for the development of the present research. Richards (1931) applied Darcy's law to unsaturated flow and established the unsaturated seepage equation, later coined Richards' equation. Neumen (1973) considered the state of saturated-unsaturated seepage flow and applied a finite element method to solve the numerical problem. Twarakavi et al. (2008) used MODFLOW (USGS, USA) and HYDRUS (Simunek et al., 1998) to simulate an infiltration experiment and an ideal example at regional scale. The results showed that the coupling model can solve the unsaturated-saturated flow problem well. Zhu et al. (2012) established a saturated-unsaturated coupling numerical model based on the vertical flow between the saturated and the unsaturated zone. Subsequently, the saturated-unsaturated seepage flow theory has been widely used (Chen et al., 2020; Diouf et al., 2020).

The overall objective of the present study is to develop and verify a saturated-unsaturated coupling model of groundwater flowing into seepage wells. Specific objectives include: 1) to carry out a physical simulation experiment, using a sand tank, and obtain the water yield, as well as the aquifer and shaft head information during pumping of seepage wells; 2) to establish a saturated-unsaturated coupling model and simulate the water intake of seepage wells; 3) to explore the critical drawdown of seepage wells when the river disconnects from the aquifer; 
and 4) to reveal a variation tendency of the unsaturated zone between river and groundwater with the drawdown of the shaft. The saturated-unsaturated coupling model can simulate water intake from seepage wells adequately both in saturated and unsaturated conditions, which can help predict water yield and guide the design of seepage wells.

\section{Materials and methods}

\subsection{Laboratory experiment}

A rectangular sand tank (with a length of $3.63 \mathrm{~m}$, a width of $0.5 \mathrm{~m}$, and a height of $1.13 \mathrm{~m}$ ) was designed to simulate the groundwater flow into the seepage well, as shown in Fig. 1. The sand tank was made of $10 \mathrm{~mm}$ thick steel and $5 \mathrm{~mm}$ thick angle steel (reinforced on the front and back sides). Sand with particle sizes from 0.25 to $1.0 \mathrm{~mm}$ was used to simulate aquifer media. One hundred and eighty observation holes on the front and back sides of the sand tank were designed to observe the water level of the aquifer. Four water intakes were set up at the bottom of the sand tank. Before the test, the sand tank was filled with water from the bottom to the top to remove the air in the sand tank. During the test, four water intakes were closed. A hole was made on the back of the sand tank to link the shaft. A water tank on the top of the sand tank was used to continuously recharge the sand tank during the test. The setup also included an overflow tank, to keep the water level at the top of the sand tank constant. When the water level exceeded the overflow height, the water would flow out through the overflow hole. On top of the sand, two kinds of permeable materials, color banded cloth and gauze, were applied to simulate riverbeds with different leakage capacities. A color banded cloth represented a river with weak leakage capacity and gauze represented a river with good leakage capacity. A layer of pebbles was laid on top of the permeable materials to simulate the riverbed media. The bottom of the sand tank was paved with a layer of pebbles for better water filling. Tensiometers were placed at the bottom of the river to record the occurrence of the unsaturated zone. Distilled water was used in the experiment.

Seepage wells were designed with five galleries, a single shaft, and five chambers, and five radiant pipes were installed in each chamber (Fig. 1). The length of each radiate pipe was $25 \mathrm{~cm}$, four of which had an elevation angle of $45^{\circ}$, while the angle of the fifth was $90^{\circ}$. The 
length of each gallery between the two adjacent chambers (with a side length of $10 \mathrm{~cm}$ ) was 50 $\mathrm{cm}$. The experiments involved three different drawdowns of the shaft for each type of river with different leakage capacities, giving a total of six test schemes. The flow rate was recorded by a measuring cylinder and a triangular weir.

After installing all the required instruments, the sand was saturated slowly from the bottom of the sand tank to the top by opening the water intakes at the bottom. The saturation process was carried out over the course of $12 \mathrm{~h}$ to remove air in the sand. After saturation, the water level in the tank was $8 \mathrm{~cm}$ higher than the top surface of the sand. Before the start of the experiment, the water intake at the sand tank bottom was closed. The water used in the experiment was supplied from the water tank. Meanwhile, the initial head of the observation holes was recorded. Then, seepage wells began pumping. When the pumping was stable, the flow rate of the seepage wells and the head of the observation holes were recorded. Seepage wells stopped pumping until the final drawdown test was completed.

After finishing the experiment, the hydraulic conductivity of sand was measured by the standpipe method (Chen, 2000), and moisture characteristic parameters of sand were determined by the sandy funnel method ( $\mathrm{Li}$ et al., 2011). These measured parameters can provide input information for the numerical model.

\subsection{Saturated-unsaturated coupling model}

The coupled seepage-pipe flow model was developed by (Chen et al., 2003) to calculate the groundwater flowing to horizontal well. However, the differential equation of saturated seepage no longer applies when the unsaturated zone appears. Therefore, to describe the unsaturated groundwater flow caused by pumping, the governing equation for the saturated groundwater flow should be modified into the "mixed form" of Richards' equation, as follows

(Thoms et al., 2006):

$$
\frac{\partial}{\partial x}\left[K_{x}(\psi) \frac{\partial H}{\partial x}\right]+\frac{\partial}{\partial y}\left[K_{y}(\psi) \frac{\partial H}{\partial y}\right]+\frac{\partial}{\partial z}\left[K_{z}(\psi) \frac{\partial H}{\partial z}\right]+W=\frac{\partial H}{\partial t}\left[\Theta(\psi) S_{S}+C(\psi)\right]
$$

where $H$ is the groundwater head; $K(\psi)$ is the unsaturated hydraulic conductivity which is a 
function of the pressure head $\psi ; \Theta(\psi)$ is the effective saturation as a function of the pressure head; $C(\psi)$ is the specific moisture capacity; $W$ is the volumetric flux per unit volume representing source(s) and/or $\operatorname{sink}(\mathrm{s}) ; S_{s}$ is the specific storage, and $t$ is time.

As the aquifer becomes fully saturated, the Richards' equation converges to the general flow equation used by MODFLOW (Harbaugh, 2005) for saturated subsurface flow:

$$
\frac{\partial}{\partial x}\left[K_{x, s a t} \frac{\partial H}{\partial x}\right]+\frac{\partial}{\partial y}\left[K_{y, s a t} \frac{\partial H}{\partial y}\right]+\frac{\partial}{\partial z}\left[K_{z, s a t} \frac{\partial H}{\partial z}\right]+W=S_{s} \frac{\partial H}{\partial t}
$$

where $K_{x, \text { sat }}$ is the saturated hydraulic conductivity $(\mathrm{m} / \mathrm{d})$.

The soil characteristic functions $K(\psi), \Theta(\psi)$, and $C(\psi)$ have been represented in the literature by several different empirical and theoretical methods (Haverkamp et al., 1977; Millington and Quirk, 1961; Mualem and Yechezkel, 1976; van Genuchten, 1980; White and Broadbridge, 1988). In this study, van Genuchten soil characteristic functions have been used. The functions are as follows:

$$
\begin{gathered}
\Theta_{e}(\psi)=\frac{\Theta-\Theta_{r}}{1-\Theta_{r}}=\left\{\begin{array}{l}
\frac{1}{\left[1+(|\alpha \psi|)^{n v}\right]^{m}} \quad \psi<0 \\
0 \quad \psi \geq 0
\end{array}\right. \\
C\left(\Theta_{e}\right)=\frac{\partial \theta}{\partial \psi}=-\frac{n_{e} m \alpha\left(1-\Theta_{r}\right)_{\Theta}}{1-m} \Theta_{e}^{1 / m}\left(1-\Theta_{e}^{1 / m}\right)^{m} \\
K_{r}\left(\Theta_{e}\right)=\Theta_{e}^{1 / 2}\left[1-\left(1-\Theta_{e}^{1 / m}\right)^{m}\right]^{2}
\end{gathered}
$$

where $\Theta_{r}$ is the residual soil saturation; $n_{v}, m$ are the soil parameters $\left(m=1-1 / n_{v}\right)$ representing the degree of pore-size uniformity; and $\alpha$ is the parameter representing the inverse characteristic length of the soil pores. A detailed description is described by (van Genuchten, 1980).

Eq. 1 combined with other definite conditions can be solved by the finite difference method. The saturated-unsaturated coupling process in MODFLOW (developed by USGS, USA) has details on how to incorporate the pressure-head dependency within the hydraulic conductivity, as well as storage terms for the unsaturated cells, and the capability and availability of incorporation (Thoms et al., 2006).

Munson et al. (2002) described the flow in the pipe using the Darcy-Weisbach equation 
(Eq. 6) which is suitable for laminar and turbulent flow:

$$
\Delta h=f \cdot \frac{l}{d} \cdot \frac{u^{2}}{2 g}
$$

Then, the flow velocity and volumetric flow rate are expressed as:

$$
\begin{gathered}
u=\sqrt{\frac{2 g d}{f} \frac{\Delta h}{l}} \\
Q_{p}=A \cdot u=\frac{\pi d^{2}}{4} \cdot \sqrt{\frac{2 g d}{f} \frac{\Delta h}{l}}
\end{gathered}
$$

where $l$ is the length of the flow path; $g$ is the gravity acceleration $\left(\mathrm{m} / \mathrm{s}^{2}\right) ; u$ is the average flow velocity in the pipe (m/s);A is the cross-sectional area of the pipe $\left(\mathrm{m}^{2}\right) ; d$ is the diameter of the pipe (m); and $f$ is the friction factor determined by different equations according to different flow regimes(Colebrook and White, 1937; Munson et al., 2002).

$$
f= \begin{cases}\frac{64}{R e} & \operatorname{Re} \leqslant 3000 \\ \frac{0.316}{R e^{0.25}} & 3000 \leqslant \operatorname{Re} \leqslant 10000 \\ \frac{1}{4}\left(\log _{10} 3.71 \frac{d}{e}\right)^{-2} & 10000 \leqslant \operatorname{Re}\end{cases}
$$

Therefore, the exchange flow rate between the aquifer and pipes and the flow rate in the pipes is as follow (Wang et al., 2013) :

$$
Q_{p}= \begin{cases}\frac{\pi \mathrm{d}^{2}}{4} \frac{\mathrm{d}^{2} \mathrm{~g}}{32 v} \frac{\Delta \mathrm{H}}{1} & \mathrm{Re} \leqslant 3000 \\ \frac{\pi \mathrm{d}^{2}}{4} \frac{2 \mathrm{gd}}{0.316}\left(\frac{\mathrm{d}}{\mathrm{v}}\right)^{0.25}\left(\frac{1}{v}\right) \frac{\Delta \mathrm{H}}{1} & 3000 \leqslant \mathrm{Re} \leqslant 10000 \\ \frac{\pi \mathrm{d}^{2}}{4} 8 \mathrm{gd}\left(\log _{10} 3.71 \frac{\mathrm{d}}{\mathrm{e}}\right)^{2} \frac{1}{v} \frac{\Delta \mathrm{H}}{1} & 10000 \leqslant \mathrm{Re} \\ Q_{e}=C\left(H_{p}-H\right) & \end{cases}
$$

where $Q_{e}$ is the exchange flow rate between the aquifer and pipe; $Q_{p}$ is the flow rate in seepage 
wells $\left(\mathrm{m}^{3} / \mathrm{d}\right) ; C$ is the conductance of seepage wells $\left(\mathrm{m}^{2} / \mathrm{d}\right) ; \mathrm{H}_{\mathrm{p}}$ is the head of pipe flow $(\mathrm{m}) ; \pi$ is the mathematical constant pi (unitless); $\Delta \mathrm{H}$ is the head loss $(\mathrm{m}) ; v$ is the average flow velocity in the well pipe $(\mathrm{m} / \mathrm{s})$; e is the coarseness degree of the inner wall of the well pipe, and $v$ is the kinematic viscosity of water $\left(\mathrm{m}^{2} / \mathrm{d}\right)$.

Based on the discretized grid of the seepage well, the water balance is satisfied at the radiate pipe node $i$ when the flow reaches the steady-state, as follows:

$$
\sum_{j=1}^{n_{p}} Q_{p, i . j}+Q_{e}=0
$$

where $j$ is the number of well nodes connected to well node $i, n_{p}$ is the total number of well nodes are connected to well node $i$, and $Q_{p, i, j}$ is the flow rate from the well node $i$ to the well node $j$. Then, the seepage flow in the aquifer is coupled with the pipe flow in the radiate bore by the exchange flow between the radiate bore and the aquifer.

Three variables (the head difference in the pipe, the average flow velocity, and the Reynolds number) are dependent on each other. Therefore, an iterative scheme must be used to solve these equations. Further, these equations are coupled into Eq. 2 by treating the exchange flow rate as the sinks of finite difference cells.

This mathematical model can be solved numerically. At the start of computation, the elevation of the top of the well nodes is set to the initial head of the well nodes, and the initial flow regime is assumed laminar. Then, exchange flow rates are computed using the initial head of the finite difference cells. Furthermore, the distribution of the flow rates through the seepage well is determined. Based on the distribution of flow rates and the diameter of the well pipe, one can get the Reynolds numbers, which are used to select the appropriate equation to calculate the new heads in the seepage well. The new heads of the seepage well can be calculated, and are used to repeat the calculation in the above Equation. The exchange flow rates after these iterations are added to finite difference equations as a sink to solve the new heads of the aquifer. Then, the new exchange flow rates are determined according to the new heads of both the aquifer and the well nodes, which are used to repeat the calculation above. The iteration for solving groundwater heads stops when the maximum absolute head differences of two 
successive iterations meet the criteria of precision. Finally, the saturated-unsaturated coupling model is used to solve the problem of the seepage well with a large drawdown in which the head loss inside the well pipe and unsaturated flow beneath the streambed layer are considered. A detailed description can be found elsewhere (Wang et al., 2017; Wang and Zhang, 2008).

In this study, the simulated river at the top of the sand tank was set as the river boundary. The bottom and sidewalls of the sand tank were set as zero flow boundary as there is no exchange with the outside. The head of the shaft was set as the constant head boundary during pumping. From this, a hydrogeological conceptual model was established.

To evaluate the performance of the model, statistical parameters such as relative errors (RE), correlation coefficient $\left(\mathrm{R}^{2}\right)$, and root-mean-square deviation (RMSD) were used (Zheng et al., 2020). Smaller values of RE, RMSE and higher values of $\mathrm{R}^{2}$ show a better performance of the model. The equations are shown as follows:

$$
\begin{gathered}
\mathrm{RMSD}=\sqrt{\sum_{\mathrm{i}=1}^{\mathrm{N}}(\text { simi-obsi })^{2} / \mathrm{N}} \\
\mathrm{R}^{2}=\frac{\sum_{1}^{\mathrm{N}}(\operatorname{simi}-\overline{\text { sim }})(\mathrm{obsi}-\overline{\mathrm{obs}})}{\sqrt{\sum_{1}^{\mathrm{N}}(\operatorname{simi}-\overline{\mathrm{sim}})^{2}} \sqrt{\sum_{1}^{\mathrm{N}}(\mathrm{obsi}-\overline{\mathrm{obs}})^{2}}} \\
\mathrm{RE}=(\overline{\operatorname{sim}}-\overline{\mathrm{obs}}) / \overline{\mathrm{obs}}
\end{gathered}
$$

where $\mathrm{N}$ is the total number of the simulation or observation data; $\mathrm{i}$ is the ith simulation or observation data; sim is the simulation data; obs is the observation data; $\overline{\text { obs }}$ is the average of the observation data; $\overline{\operatorname{sim}}$ is the average of the simulation data.

Finally, the contents of this paper and the relationship between each part were shown in Fig. 2.

\section{Results and discussion}

\subsection{The results of the experiment}

The drawdown of the shaft and the flow rate of the seepage wells were recorded throughout the experiment (Fig. 3). For the simulated river with a strong leakage capacity, the flow rate increased linearly with the increase of the drawdown in the shaft, which indicated that the water 
yield of the seepage wells can be guaranteed due to a sufficient recharge source. However, for the simulated river with a weak leakage capacity, the previously increasing rate of flow rate decreased during the third stage (B2-D3). This was due to the limited recharge capacity of the river preventing the aquifer from being recharged quickly enough, which led to the river being disconnected from the groundwater, thereby forming an unsaturated zone. The unsaturated zone was also observed by tensiometers during this period. Furthermore, for the same drawdown, the flow rate of the river with a strong leakage capacity was larger than that of the river with a weak leakage capacity.

Fig. 4 shows the drawdown contours of the aquifer in each scheme when the flow rate became stable. The drawdown of the aquifer increased with the increase of the shaft drawdown and was always smaller than that in the shaft. Comparing the schemes in B1 and B2, it can be found that the drawdowns in the B2 schemes were larger than those in B1. This suggests that the timely recharge of rivers mitigated the decrease of aquifer levels. It is also found that the drawdown of the aquifer increases with proximity to the seepage wells. These results indicate that the water yield of the seepage wells mainly came from direct recharge of the nearby aquifer.

As shown in Fig. 5, the drawdown of the aquifer increased with the increment of drawdown for the shaft but it was smaller than that in the shaft. The drawdown of the aquifer increased first and then decreased from top to bottom and reach the maximum near the seepage wells. It indicates that the drawdown of the upper aquifer was mitigated by the recharge of the river. Water to the seepage wells was also supplied from aquifer under the seepage wells. By combining Fig. 4 and 5, it can be deduced that groundwater was supplied from the aquifer surrounding the seepage wells, and the groundwater flowing to the seepage wells showed clear three-dimensional flow characteristics.

Six samples were taken from different positions in the sand tank and hydraulic conductivities of the sand layer were measured by the standpipe method (shown in Tab.1). The hydraulic conductivities ranged from 31.84 to $47.82 \mathrm{~m} / \mathrm{d}$, with an average of $40.76 \mathrm{~m} / \mathrm{d}$. As shown in Fig. 6, the desorption process and the moisture absorption process were fitted by using the soil characteristic function. There was a good hysteresis between the sorption and 
desorption curves, and soil characteristic function fitted the measured data well. Therefore, the moisture characteristic parameters of sand were determined (Tab.2).

\subsection{Model and Simulation evaluations}

Six schemes were simulated by using the saturated-unsaturated coupling model, and the model was verified by experimental data using the sand tank setup. Table 3 presents the simulated and experimental results of the flow rate and their errors. It can be found that the calculated and observed flow rates were in good agreement and that flow rates increased with increasing drawdown of the shaft. The largest absolute error between the calculated and the experimental flow rates was $0.0148 \mathrm{~L} / \mathrm{s}$, and the relative error was less than $4 \%$.

To further evaluate the performance of the model, the simulated results (including the water yield of seepage wells and the drawdown of the observation holes) and the experimental data were compared in Fig. 7 ( $a$ and $b$ ). The model effectively simulated the flow rate of the seepage wells and drawdown. For the river with strong leakage capacity, the flow rate and drawdown had $\mathrm{R}^{2}$-values of 0.99 and 0.98 , respectively. Root-mean-square deviations (RMSD) were $0.0079 \mathrm{~L} / \mathrm{s}$ and $0.0114 \mathrm{~m}$, respectively, and relative errors (RE) for flow rate and drawdown were $1.96 \%$ and $-0.13 \%$, respectively. For the river with weak leakage capacity, the $\mathrm{R}^{2}, \mathrm{RMSD}$, and $\mathrm{RE}$ for flow rate were $0.99,0.0099 \mathrm{~L} / \mathrm{s}, 2.54 \%$, respectively, and for drawdown were $0.98,0.0129 \mathrm{~m}$, and $-2.58 \%$, respectively. These results show the feasibility of using this model to simulate water intake in seepage wells both in saturated and unsaturated conditions. The final model parameters are $K v=45 \mathrm{~m} / \mathrm{d}, \mathrm{K}_{\mathbf{h}}=29.5 \mathrm{~m} / \mathrm{d}, \mathrm{S}_{\mathbf{y}}=0.2$.

\subsection{Determination of the critical drawdown}

Due to the limitations of the experimental conditions, only six representative schemes have been designed to simulate the water intake of seepage wells. Disconnection between the river and groundwater aquifer appeared in scheme B2-D3, forming an unsaturated zone. However, the existing coupled seepage-pipe flow model was only suitable for saturated seepage flow, and the unsaturated unit was treated as an inactive unit without water exchange, leading to calculation errors. Therefore, it was of great significance to determine the critical drawdown of the shaft when the river and groundwater disconnected. To determine the critical drawdown, 
the existing coupled seepage-pipe flow model and the saturated-unsaturated coupling model were used to calculate the water yield of seepage wells under different drawdowns of the shaft.

As illustrated in Fig. 8, the calculation results of the two models were very close when the drawdown of the shaft was less than $33.588 \mathrm{~cm}$, which indicated that both models can be used to calculate the water intake of seepage wells under saturated conditions. However, the water yield calculated by the former model rapidly decreased to 0 once the drawdown went beyond $33.588 \mathrm{~cm}$. When the saturated-unsaturated coupling model was used to calculate the water yield, the water yield continued to increase at first (but the growth rate decreased) after the drawdown of the shaft was input to be larger than $33.588 \mathrm{~cm}$, and finally became stable at drawdowns above $44 \mathrm{~cm}$. Compared to the calculation results of the two models, the critical depth of disconnection between the river and groundwater was finally determined to be 33.588 $\mathrm{cm}$. It is worth noting that the reasonable drawdown of the shaft is very important in practical engineering. If the drawdown of the shaft is too small, the water yield will not meet the demand. However, if the drawdown of the shaft is too large, the water yield of the seepage well will not increase significantly, and the water intake efficiency will decrease.

\subsection{Variation law of the unsaturated zone}

To establish the variation tendency of the unsaturated zone, the saturated-unsaturated coupling model was used to simulate the water intake of seepage wells under different drawdowns of the shaft. Fig. 9 shows the variation of the unsaturated zone in the plane and profile. Since the critical drawdown has been determined to be $33.588 \mathrm{~cm}$, the drawdown of the shaft was set to $34,36,38,40,42,44,46$, and $48 \mathrm{~cm}$, respectively (shown in Fig. 8). As illustrated in Fig. 9, the drawdown of the aquifer increased with increasing drawdown of the shaft. Furthermore, it can be seen that the unsaturated zone area at first was very small and appeared in the center of the first layer of the model. The area of the unsaturated zone increased and expanded to the lower aquifer with the increase of shaft drawdown. Subsequently, the unsaturated zone took up all the space in the first layer and reached the fourth layer. The unsaturated zone expanded from the center of every layer to the surrounding area and from top to bottom of the model, showing a cone-shaped spatial distribution. 


\section{Conclusion}

Seepage wells are major and complex groundwater extraction structures. A fundamental understanding of unsaturation caused by pumping in seepage wells is vital for guiding the design of seepage wells. In this present study, a physical simulation test of a sand tank for water intake of seepage wells was designed. The results showed that the water yield of a river with a strong leakage capacity was larger than that of a river with a weak leakage capacity when the drawdown of the shaft was the same. There was no unsaturated phenomenon observed in the test scheme of the river with strong leakage capacity, and the relationship between water yield and drawdown of the shaft was linear. However, the growth rate of the water yield began to decrease after an unsaturated zone appeared, which was reflected in the river scheme with a weak leakage capacity. The experiment also revealed that the groundwater flowed into seepage wells showed clear characteristics of three-dimensional flow.

A saturated-unsaturated coupling model has been developed to describe how groundwater flows into seepage wells both in saturated and unsaturated conditions. The model has been verified by experimental data. The validation results for the drawdown and water yield of the river with strong leakage capacity showed root-mean-square deviations, RMSD, equal to $0.0114 \mathrm{~m}$ and $0.0079 \mathrm{~L} / \mathrm{s}$, and the correlation coefficients, $\mathrm{R}^{2}$, were 0.98 and 0.99 , respectively. For the river with weak leakage capacity, the $\mathrm{R}^{2}$ and RMSD of flow rate were 0.99 and 0.0099 $\mathrm{L} / \mathrm{s}$, and for drawdown were 0.98 and $0.0129 \mathrm{~m}$. These results suggest that the model can appropriately simulate water intake in seepage wells both in saturated and unsaturated conditions, and indicate a good performance of the model. Furthermore, the critical drawdown of the shaft at the time of disconnection between the river and groundwater aquifer (forming an unsaturated zone) was determined to be $33.588 \mathrm{~cm}$. The unsaturated zone expanded from the center of each layer to the surrounding area and from top to bottom of the model, showing a cone-shaped spatial distribution.

In summary, the saturated-unsaturated coupling model described herein has a great potential to help predict the water yield of seepage wells and describe the groundwater flow field during the pumping of seepage wells both in saturated and unsaturated environments. 
These results can provide important information for designing seepage wells and at the same time help to protect the groundwater environment.

Author contributions: Xianmin Ke designed the experiment, established the model, and wrote the manuscript. Wei Wang guided the experiment, established the mathematical model, and edited the manuscript. Xiangdong $\mathrm{Xu}$ analyzed the data and draw the figures. Jinlong $\mathrm{Li}$ checked the manuscript for error and submitted the manuscript. Haiyang $\mathrm{Hu}$ collected all the experiment data. All authors participated in and finished the experiment, gave comments, and contributed to the final version of the manuscript.

Funding: This study was sponsored by the Shaanxi Geological and Mining Corporation (Grant No. KY201503). This research was also funded by the Fundamental Research Funds for the Central Universities, CHD, (Grant No. 300102290401).

Acknowledgments : We acknowledge the 908 Team of Hydrogeology and Engineering Geology, and the Research Institute of Exploration and Development, PetroChina Changqing Oilfield Branch Company for offering financial support. We acknowledge the Ecoenvironmental Protection Forum of the Yellow River Basin for giving us this opportunity to submit and publish. We are grateful to professor Peiyue Li for editing and reviewing the paper. We are sincerely grateful to all reviewers and the editors for their meaningful comments, which have helped us to improve the quality of the original manuscript.

Competing interests: The authors declare that they have no conflict of interest.

Availability of data and materials: All data, models, or codes generated or used during the study are available from the corresponding author.

\section{References}

Ameli AA, Craig JR (2018) Semi-analytical 3D solution for assessing radial collector well pumping impacts on groundwater-surface water interaction. Hydrology Research:nh2017201. doi:10.2166/nh.2017.201

Brunner P, Cook PG, Simmons CT (2011) Disconnected Surface Water and Groundwater: From Theory to Practice. Groundwater 49:460-467. 
doi:10.1111/j.1745-6584.2010.00752.x

Chang J, Ke X, Wang W, Sun, Tian G (2019 ) Field Test and Numerical Simulation on Seepage Well of Mazhen County. Journal of Yangtze River Scientific Research Institute 36:83-88.

Chen C, Wan J, Zhan H (2003) Theoretical and experimental studies of coupled seepage-pipe flow to a horizontal well. Journal of Hydrology 281:159-171. doi:10.1016/S0022-1694(03)00207-5

Chen X (2000) Measurement of streambed hydraulic conductivity and its anisotropy. Environmental Geology 39:1317-1324. doi:10.1007/s002540000172

Chen YF, Yu H, Ma HZ, Li X, Yang Z (2020) Inverse modeling of saturated-unsaturated flow in site-scale fractured rocks using the continuum approach: A case study at Baihetan dam site, Southwest China. Journal of Hydrology 584:124693-. doi:10.1016/j.jhydrol.2020.124693

Cognac KE, Ronayne MJ (2020) Changes to inter-aquifer exchange resulting from long-term pumping: implications for bedrock groundwater recharge. Hydrogeology Journal 28:1-12. doi:10.1007/s10040-020-02141-x

Colebrook CF, White CM (1937) THE REDUCTION OF CARRYING CAPACITY OF PIPES WITH AGE. Journal of the ICE 7:99-118. doi:10.1680/ijoti.1937.14682

Diouf OC, Weihermüller L, Diedhiou M, Vereecken H, Sylla SN (2020) Modelling groundwater evapotranspiration in a shallow aquifer in a semi-arid environment. Journal of Hydrology:124967. doi:10.1016/j.jhydrol.2020.124967

$\mathrm{Fu} \mathrm{L} \mathrm{(2012)} \mathrm{Study} \mathrm{on} \mathrm{the} \mathrm{rural} \mathrm{drinking} \mathrm{water} \mathrm{safety} \mathrm{guarantee} \mathrm{system} \mathrm{and} \mathrm{engineering}$ measures in arid and semi-arid area. Chang'an University

Glennon R (2007) Tales of French Fries and Bottled Water: The Environmental Consequences of Groundwater Pumping. Environmental Law 37.

Hantush MS (1961) AQUIFER TESTS ON PARTIALLY PENETRATING WELLS. American Society of Civil Engineers 87:171-195. doi:10.1029/JZ065i008p02467

Harbaugh AW (2005) MODFLOW-2005, the US Geological Survey modular groundwater model-the groundwater flow process. Center for Integrated Data Analytics Wisconsin Science Center. 
Haverkamp R, Vauclin M, Touma J, Wierenga PJ, Vachaud G (1977) A Comparison of Numerical Simulation Models For One-Dimensional Infiltration. Soil Scisocamj 41:285. doi:10.2136/sssaj1977.03615995004100020024x

Lee E, Hyun Y, Lee KK (2010) Numerical modeling of groundwater flow into a radial collector well with horizontal arms. Geosciences Journal 14:403-414. doi:10.1007/s12303-010-0037-x

Li P, Qian H (2013) Global curve-fitting for determining the hydrogeological parameters of leaky confined aquifers by transient flow pumping test. Arabian Journal of Geosciences 6(8):2745-2753. doi:10.1007/s12517-012-0567-9

Li P, Wu J, Qian H (2014) Hydrogeochemistry and Quality Assessment of Shallow Groundwater in the Southern Part of the Yellow River Alluvial Plain (Zhongwei Section), Northwest China. Earth Sci Res J 18:27-38. doi:10.15446/esrj.v18n1.34048

Li W, Li, Wang, Li (2011) Measurement of soil moisture characteristic curves of sandy medium by sandy funnel method. IEEE. doi:10.1109/ISWREP.2011.5893622

Maroney CL, Rehmann CR (2017) Stream depletion rate for a radial collector well in an unconfined aquifer near a fully penetrating river. Journal of Hydrology 547:732-741. doi:10.1016/j.jhydrol.2017.02.010

Millington RJ, Quirk JP (1961) Permeability of porous solids. Transactions of the Faraday Society 5:1200-1207. doi:10.1039/tf9615701200

Mualem, Yechezkel (1976) A new model for predicting the hydraulic conductivity of unsaturated porous media. Water Resources Research 12:513-522. doi:10.1029/WR012i003p00513

Munson BR, Young DF, Okiishi TH (2002) Fundamentals of Fluid Mechanics.

Neumen SP (1973) Saturated-unsaturated seepage by finite elements. Proc Asce 12.

Park E, Zhan H (2003) Hydraulics of horizontal wells in fractured shallow aquifer systems. Journal of Hydrology 281:147-158. doi:10.1016/S0022-1694(03)002063

Qiao XY, Wang WK, Duan L, Wang YL, Xiao P (2020) Regional groundwater cycle patterns and renewal capacity assessment at the south edge of the Junggar Basin, 
China. Environmental Earth Sciences 79. doi:10.1007/s12665-020-09045-9

Richards LA (1931) Capillary conduction through porous mediums. Journal of Applied Physics 1. doi:10.1063/1.1745010

Simunek J, Sejna M, Genuchten M (1998) The HYDRUS-2D Software Package for Simulating Water Flow and Solute Transport in Two Dimensional Variably Saturated Media, Version 2.0.

Sun K (2015) Numerical study identifying the factors causing the significant underestimation of the specific discharge estimated using the modified integral pumping test method in a laboratory experiment. Journal of Contaminant Hydrology 180:1-11. doi:10.1016/j.jconhyd.2015.07.001

Sun Q (2017) Field test study of seepage well in Mazhen. Chang'an University

Thoms R, Johnson R, Healy R (2006) User's Guide to the Variably Saturated Flow (VSF) Process to MODFLOW. Usgs Usgeological Survey.

Twarakavi N, Imnek J, Seo S (2008) Evaluating Interactions between Groundwater and Vadose Zone Using the HYDRUS-Based Flow Package for MODFLOW. Vadose Zone Journal 9. doi:10.2136/vzj2009.0190

van Genuchten MT (1980) A closed-form equation for predicting the hydraulic conductivity of unsaturated soils. Soil Science Society of America Journal 44:892898. doi:10.2136/sssaj1980.03615995004400050002x

Wang D, Wu J, Wang Y, Ji Y (2020) Finding High-Quality Groundwater Resources to Reduce the Hydatidosis Incidence in the Shiqu County of Sichuan Province, China: Analysis, Assessment, and Management. Exposure and Health 12(2):307-322. doi:10.1007/s12403-019-00314-y

Wang J (2013) Study on the high efficient development manner of groundwater in yellow river valley with thin aqufier Chang'an University

Wang W, Chen P, Zheng Q, Zheng X, Lu K (2013) A modified calculation model for groundwater flowing to horizontal seepage wells. Journal of Earth System Science 122:407-418. doi:10.1007/s12040-013-0283-1

Wang W, Liu J, Chen L, Ning L, Xue L (2009) Determination on the Reasonable Drawdown of Vertical Well of a Seepage Well. Journal of Earth Sciences and 
Environment:281-284. doi:10.3969/j.issn.1672-6561.2009.03.010

Wang W, Lv J, Xu D, Li L, Jia Y (2017) Migration of induced-infiltration stream water into nearby aquifer due to a transverse horizontal well in loess areas. Environmental Earth Sciences 76:572. doi:10.1007/s12665-017-6904-2

Wang W, Zhang G (2008) Numerical simulation of groundwater flowing to horizontal seepage wells under a river. Hydrogeology Journal 16:199-199. doi:10.1007/s10040-007-0257-y

White I, Broadbridge P (1988) Constant rate rainfall infiltration: A versatile nonlinear model: 2. Applications of solutions. Water Resources Research 24:155-162. doi:10.1029/WR024i001p00155

Wu Z, Deng C, Si J, Kan Z, Yue M (2019) Study on Optimization of New Type of Seepage Well Structure in Sponge City. Iop Conference 472:012074. doi:10.1088/1757-899X/472/1/012074

Xie Y, Cook PG, Brunner P, Irvine DJ, Simmons CT (2015) When Can Inverted Water Tables Occur Beneath Streams? Ground Water 52. doi:10.1111/gwat.12109

Zhan, H., Wang, L., V., Park, E. (2001) On the horizontal-well pumping tests in anisotropic confined aquifers. JOURNAL OF HYDROLOGY -AMSTERDAM252. doi:10.1016/S0022-1694(01)00453-X

Zhang W, Huang G, Zhan H (2008) An analytical solution for non-Darcian flow in a confined aquifer using the power law function. Advances in Water Resources 364:99-106. doi:10.1016/j.jhydrol.2008.10.009

Zheng C, Imnek J, Lu Y, Liu X, Li H (2020) Monitoring and modeling the coupled movement of water, vapor, and energy in arid areas. Journal of Hydrology 590:125528. doi:10.1016/j.jhydrol.2020.125528

Zhu, Y., Shi, L., Lin, Yang, J., M. (2012) A fully coupled numerical modeling for regional unsaturated-saturated water flow. JOURNAL OF HYDROLOGY AMSTERDAM-. 


\section{FIGURE Captions:}

Fig. 1 The description of the experimental equipment

Fig. 2 The framework illustrating the logic of the study

Fig. 3 The relationship between experimental flow rate and drawdown. B1 and B2 represent rivers with strong and weak leakage capacities, respectively, and D1 to D3 represent the first to third drawdown, respectively

Fig. 4 Top view (XOY plane) of experimental drawdown contour map in each period. The black lines are the top view of the seepage wells. The unit of drawdown is centimeters

Fig. 5 Cross-sectional view (XOZ profile) of experimental drawdown contour map in each period. The black lines are the profiles of seepage wells. The unit of drawdown is centimeters

Fig. 6 Fitting of soil moisture curve. The scattered points represent the measured data, and the curves are based on function fitting. The blue and red lines represent the sorption and desorption processes, respectively. The vertical and horizontal axes are soil water suction and the water content, respectively

Fig. 7 Comparison of simulated and observed results. $\mathrm{Q}_{\text {obs }}$ and $\mathrm{Q}_{\text {sim }}$ are the observed and simulated flow rates of seepage wells, respectively, and $\mathrm{S}_{\mathrm{obs}}$ and $\mathrm{S}_{\mathrm{sim}}$ are the experimental and modeled drawdown of observation holes, respectively. The black lines in the graph represent the function $\mathrm{y}=\mathrm{x}$. The blue and red circles represent rivers with weak and strong leakage capacity, respectively

Fig. 8 The relationship between the simulated flow rate and drawdown. The red and blue lines 
are the results calculated by the former model and the saturated-unsaturated coupling model, respectively. The green square represents the water yield at the critical drawdown

Fig. 9 The variation of the unsaturated zone. M-D1, M-D2, M-D3, M-D4 represent drawdown of the shaft with $34,38,42,46 \mathrm{~cm}$, respectively, the gray area represents the unsaturated zone, and the contours represent the variation of the drawdown. The unit of drawdown is centimeters

\section{Tables:}

Table 1 Hydraulic conductivity of the sand

\begin{tabular}{cccccccc}
\hline Number & 1 & 2 & 3 & 4 & 5 & 6 & Average \\
\hline$K(\mathrm{~m} / \mathrm{d})$ & 37.36 & 38.65 & 44.01 & 45.39 & 47.82 & 31.84 & 40.76 \\
\hline
\end{tabular}

Table 2 Moisture characteristic parameters of sand $\left(\theta_{\mathrm{s}}\right.$ : saturated water content; $\theta_{\mathrm{r}}$ Residual water content; $\alpha$ and $\mathrm{n}$ are characteristic parameters)

\begin{tabular}{ccccc}
\hline Process & $\theta_{\mathrm{s}}$ & $\theta_{\mathrm{r}}$ & $\alpha$ & $\mathrm{n}$ \\
\hline desorption & 0.365 & 0.093 & 0.039 & 6.644 \\
absorption & 0.365 & 0.093 & 0.041 & 6.523 \\
\hline
\end{tabular}

Table 3 Comparison of calculated and simulated flow rates

\begin{tabular}{ccccc}
\hline Scheme & $\begin{array}{c}\text { Observed flow rate } \\
(\mathrm{L} / \mathrm{s})\end{array}$ & $\begin{array}{c}\text { Calculated flow rate } \\
(\mathrm{L} / \mathrm{s})\end{array}$ & $\begin{array}{c}\text { Absolute error } \\
(\mathrm{L} / \mathrm{s})\end{array}$ & $\begin{array}{c}\text { Relative error } \\
(\%)\end{array}$ \\
\hline B1-D1 & 0.2916 & 0.2963 & 0.0047 & 1.61 \\
B1-D2 & 0.4964 & 0.5032 & 0.0017 & 1.37 \\
B1-D3 & 0.7357 & 0.7523 & 0.0166 & 2.26 \\
B2-D1 & 0.2810 & 0.2813 & 0.0003 & 0.11 \\
B2-D2 & 0.4793 & 0.4941 & 0.0148 & 3.09 \\
B2-D3 & 0.5959 & 0.6152 & 0.0193 & 3.24 \\
\hline
\end{tabular}


Figures

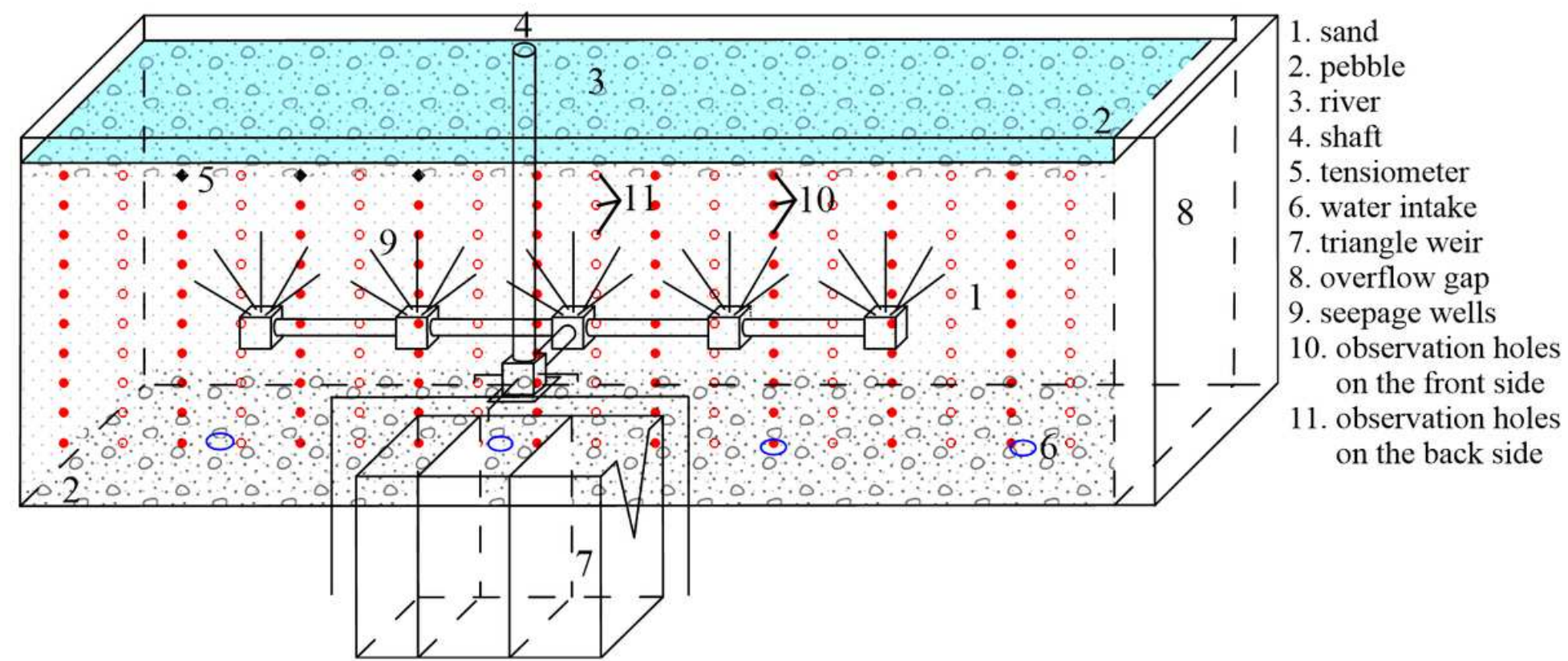

Figure 1

The description of the experimental equipment 


\section{A Saturated-unsaturated coupling model of groundwater flowing into seepage wells}
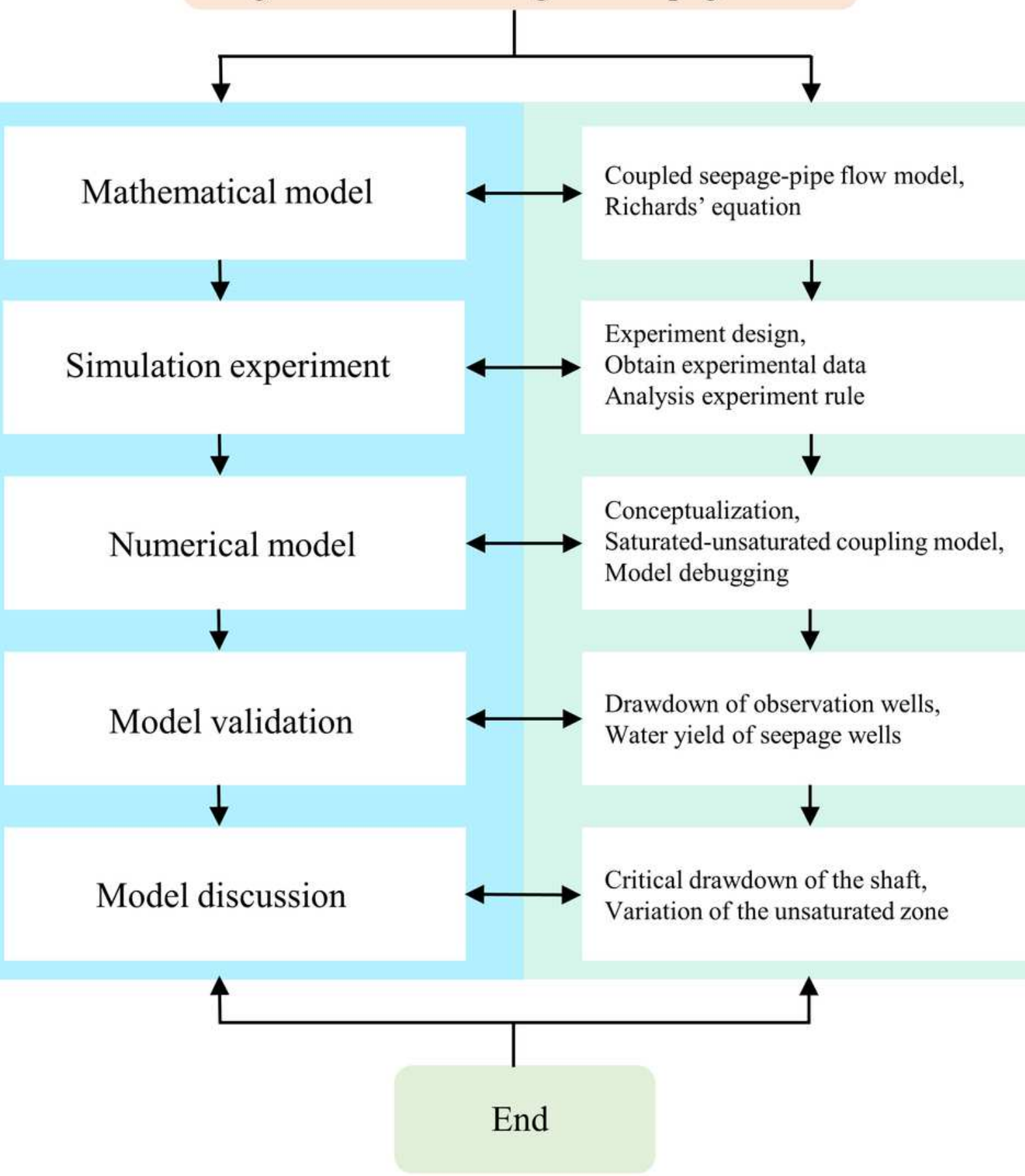

\section{Figure 2}

The framework illustrating the logic of the study 


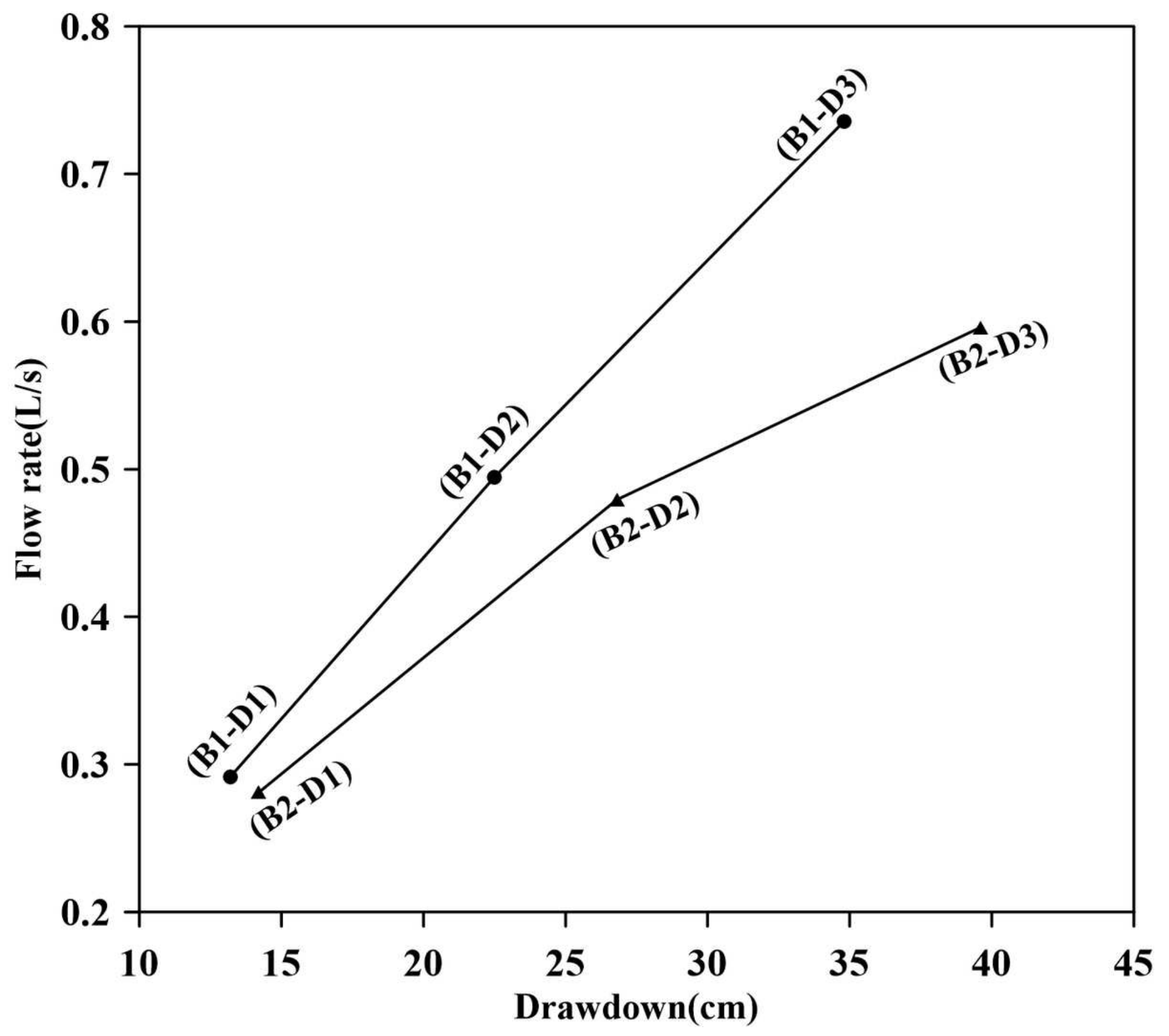

Figure 3

The relationship between experimental flow rate and drawdown. B1 and B2 represent rivers with strong and weak leakage capacities, respectively, and D1 to D3 represent the first to third drawdown, respectively 

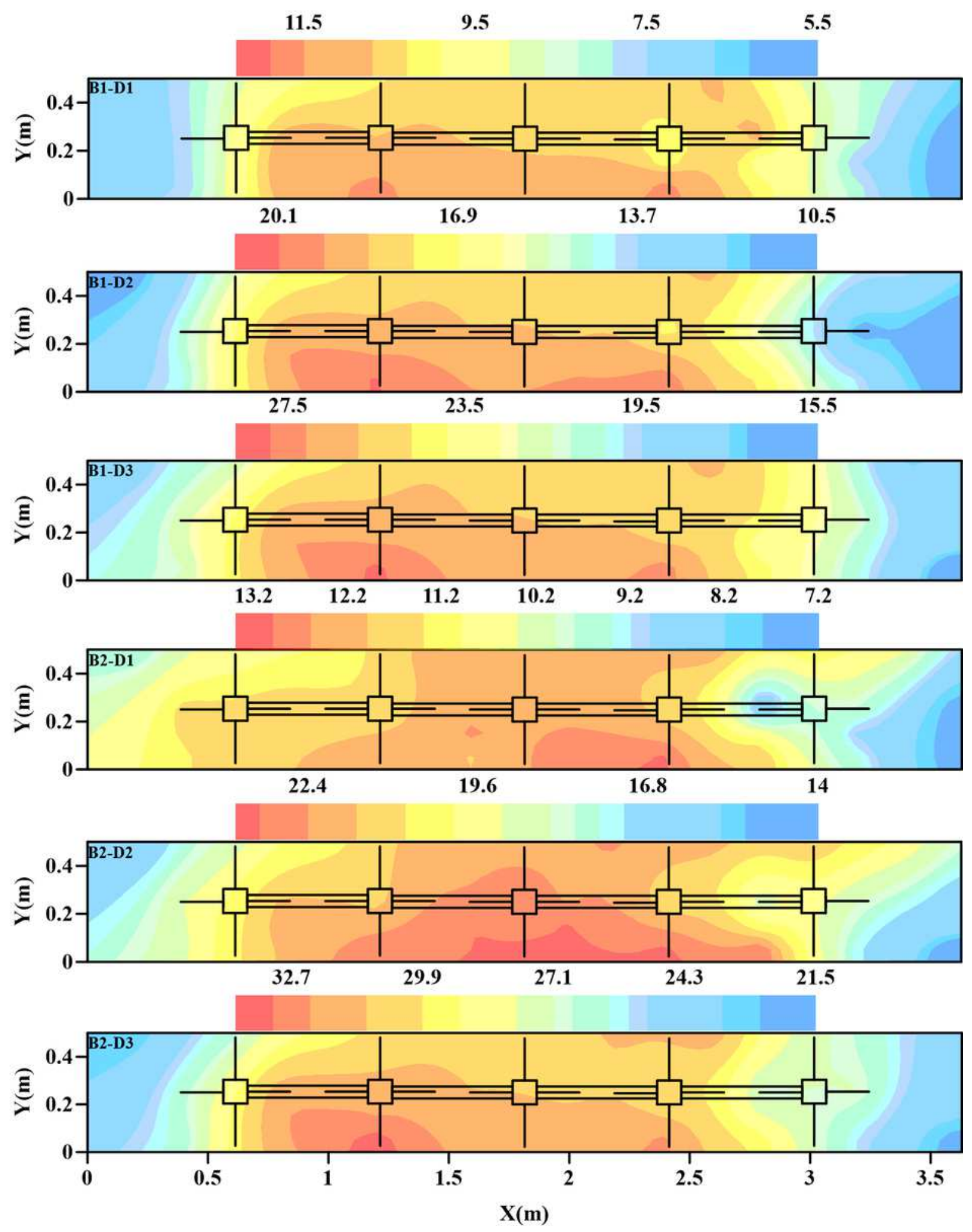

\section{Figure 4}

Top view (XOY plane) of experimental drawdown contour map in each period. The black lines are the top view of the seepage wells. The unit of drawdown is centimeters 

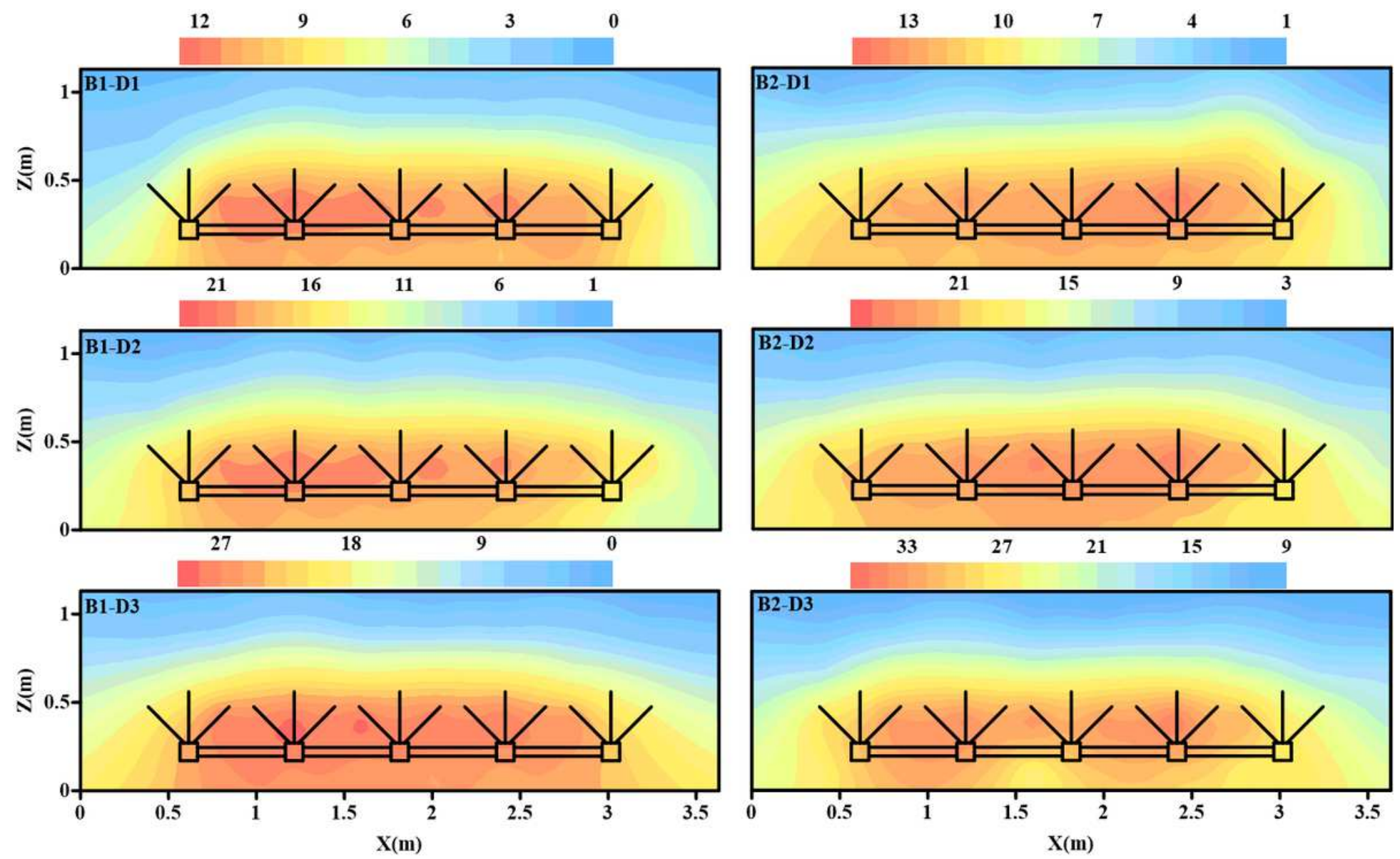

Figure 5

Cross-sectional view (XOZ profile) of experimental drawdown contour map in each period. The black lines are the profiles of seepage wells. The unit of drawdown is centimeters
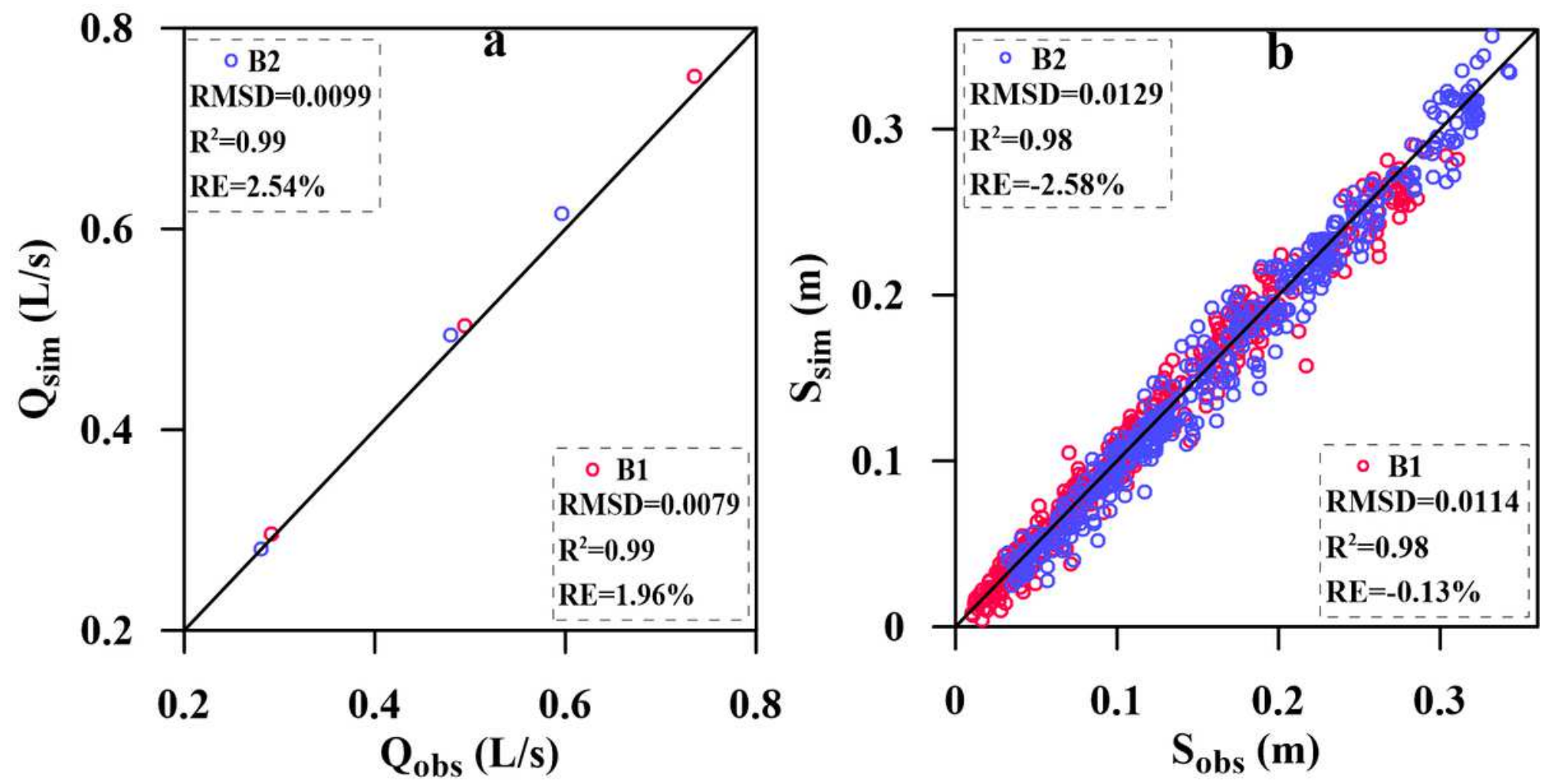
Figure 6

Fitting of soil moisture curve. The scattered points represent the measured data, and the curves are based on function fitting. The blue and red lines represent the sorption and desorption processes, respectively. The vertical and horizontal axes are soil water suction and the water content, respectively

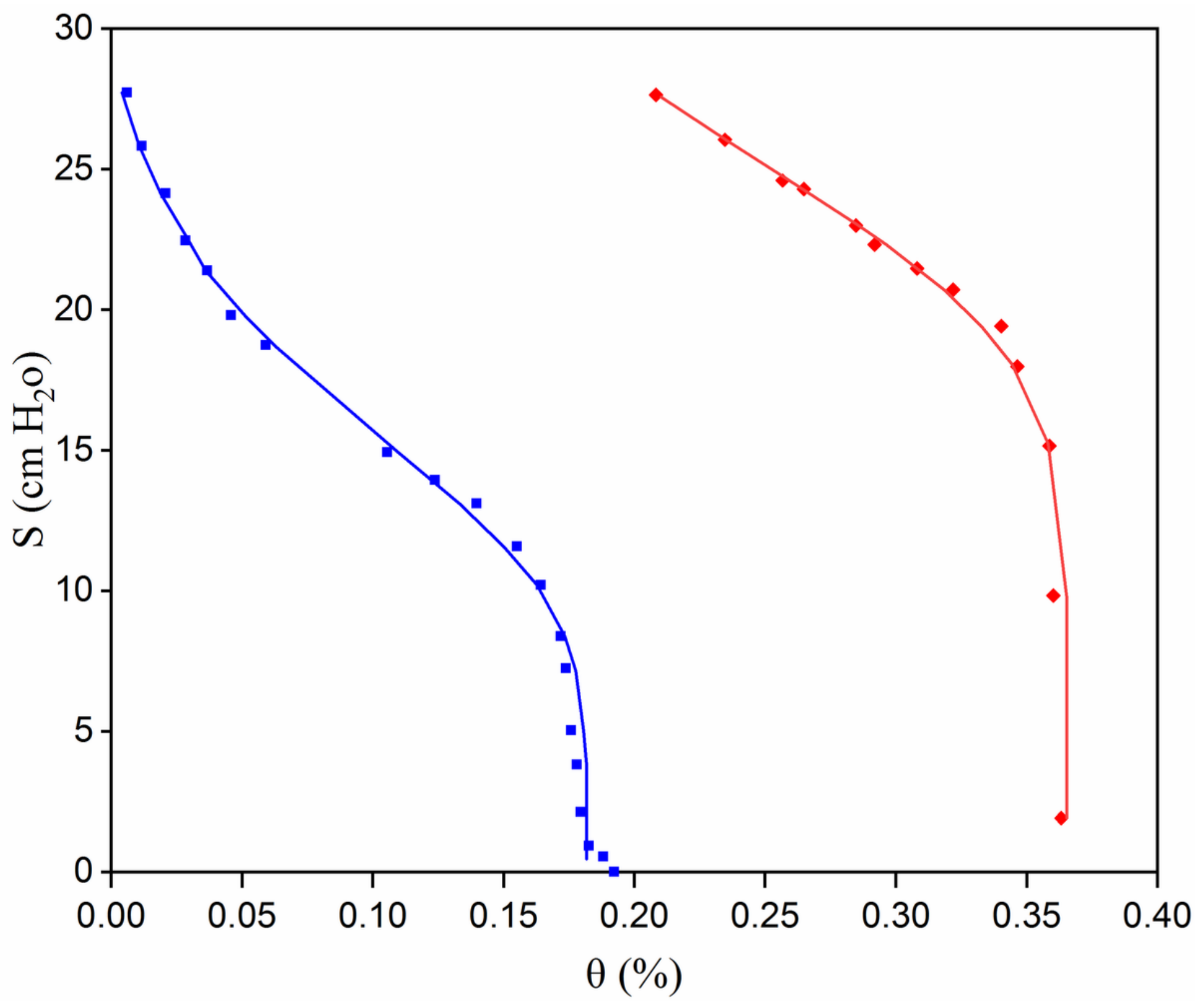

Figure 7

Comparison of simulated and observed results. Qobs and Qsim are the observed and simulated flow rates of seepage wells, respectively, and Sobs and Ssim are the experimental and modeled drawdown of observation holes, respectively. The black lines in the graph represent the function $y=x$. The blue and red circles represent rivers with weak and strong leakage capacity, respectively 


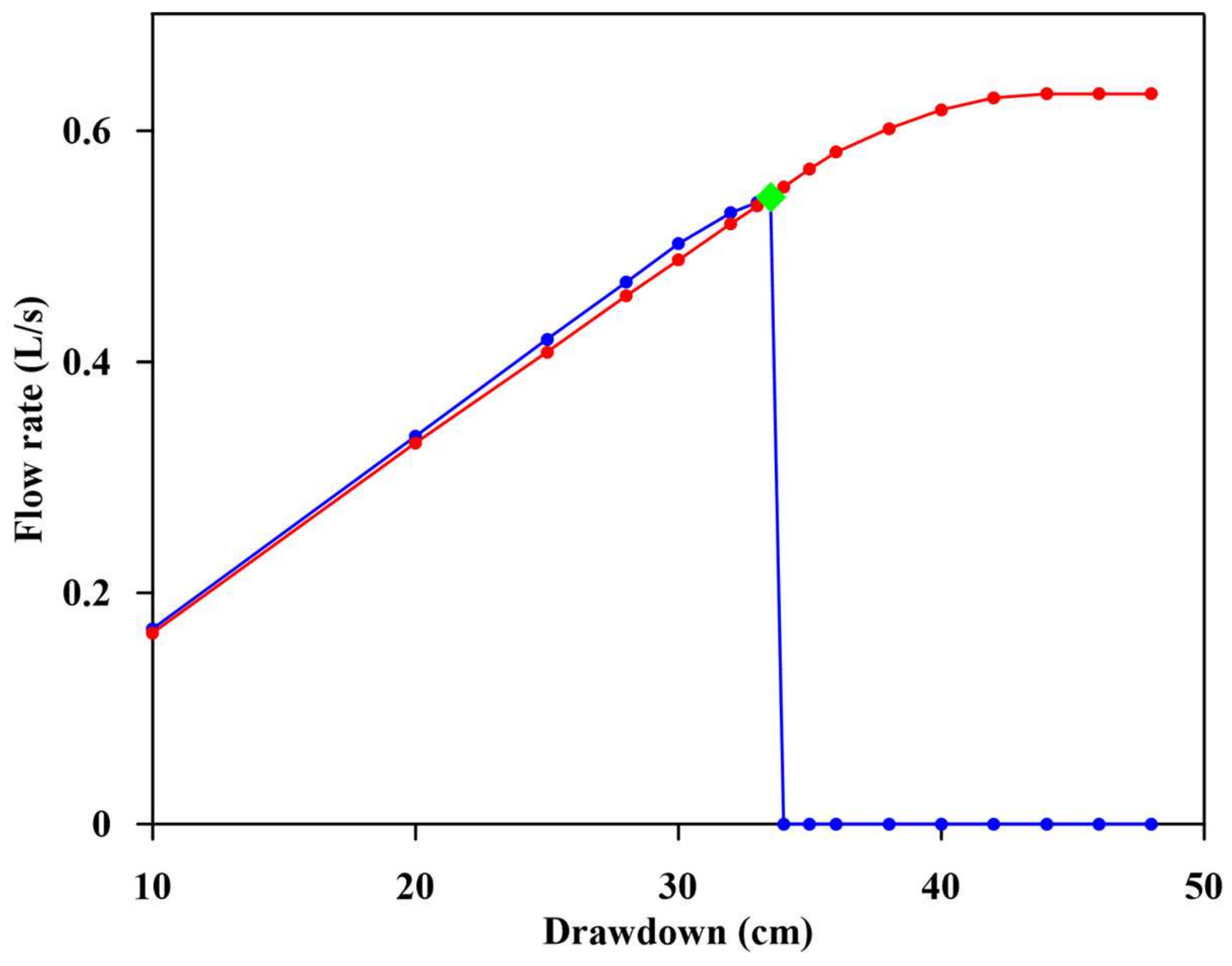

Figure 8

The relationship between the simulated flow rate and drawdown. The red and blue lines are the results calculated by the former model and the saturated-unsaturated coupling model, respectively. The green square represents the water yield at the critical drawdown 

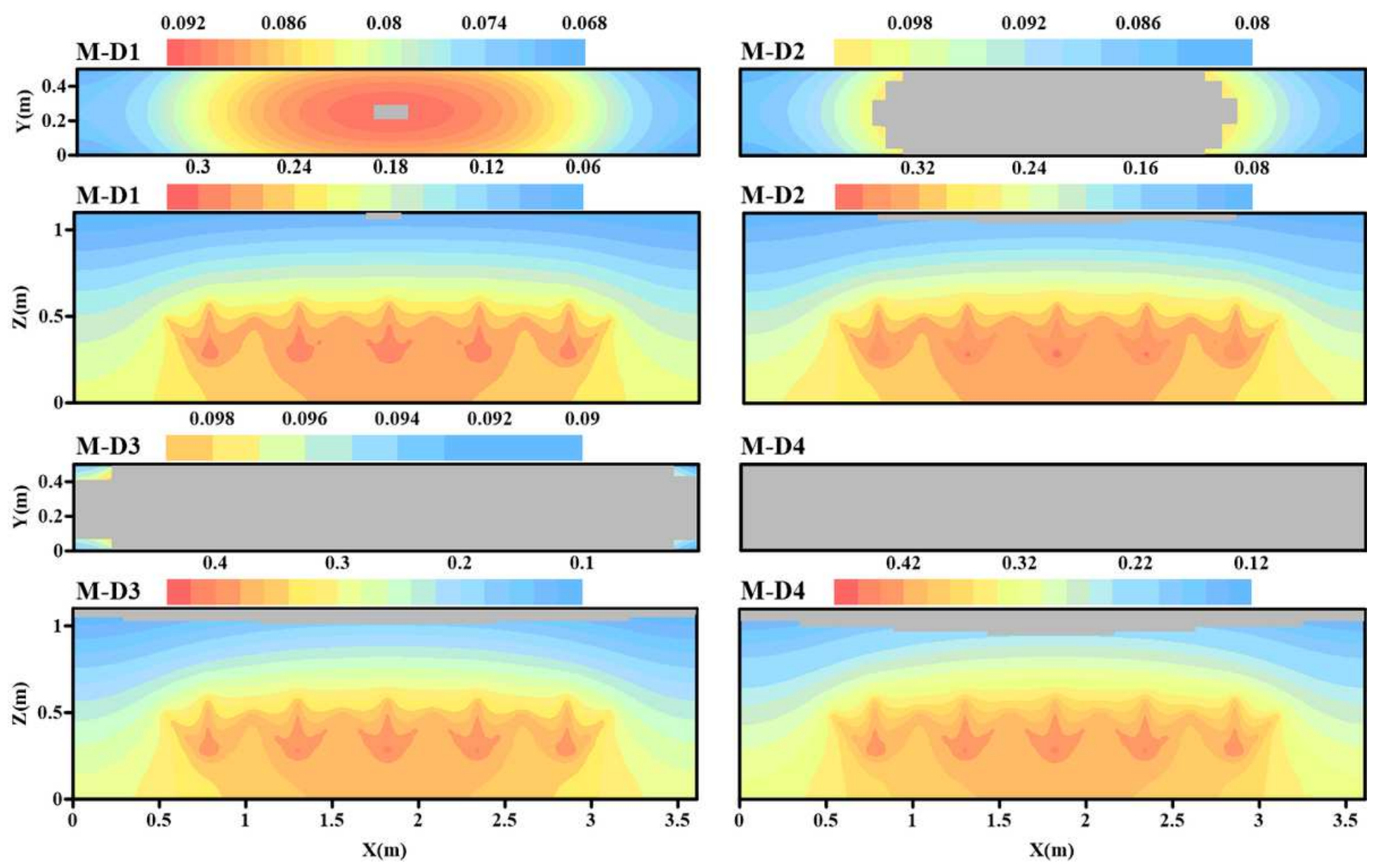

M-D4

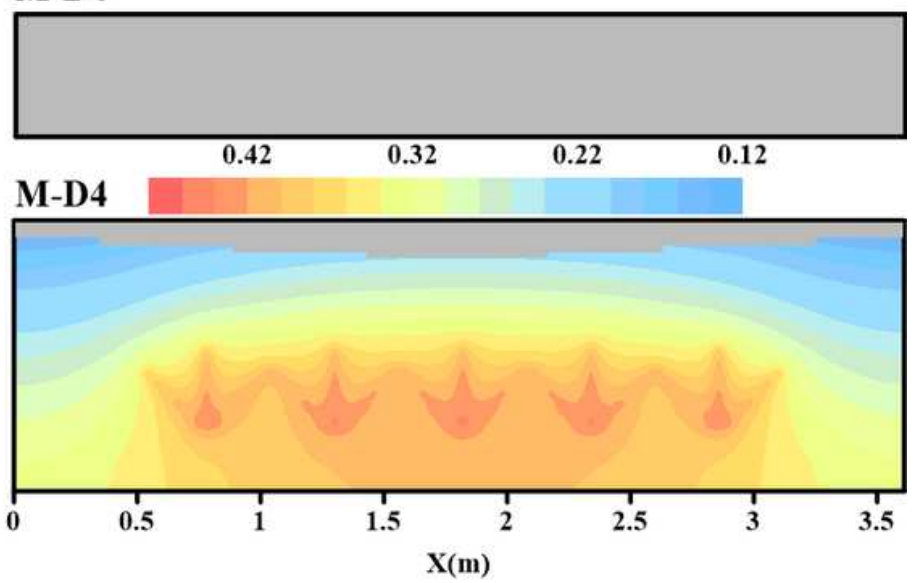

Figure 9

The variation of the unsaturated zone. M-D1, M-D2, M-D3, M-D4 represent drawdown of the shaft with 34, $38,42,46 \mathrm{~cm}$, respectively, the gray area represents the unsaturated zone, and the contours represent the variation of the drawdown. The unit of drawdown is centimeters 